Principles of Microbe and Cell Cultivation. By S. John Pirt. Pp. $\mathrm{x}+274$. (Blackwell Scientific: Oxford and London; Halstead: New York, 1975.) $£ 10.50$.

Thrs book has been written for students of microbiology and as a reference book for research workers involved in the problem of microbial cell growth. The treatment of the subject is a clear simple mathematical one which should enable the reader readily to understand the dynamics of the different techniques of cell cultivation.

The book is divided into 25 chapters with an appendix of the symbols and abbreviations used. The initial chapters are devoted to an historical outline and to a consideration of the general parameters of cell growth. Batch and continuous culture methods of cell growth are then discussed. The next four chapters deal with the supply of energy and oxygen to growing cells. The other factors affecting growth, general nutrition, temperature, $p \mathrm{H}$ and water activity are dealt with in separate chapters. There are a number of chapters of interest to microbiologists involved in the production of materials by microbial processes, for example, product formation, growth lag, and batch cultures with substrate feeds.

The subjects of interest to microbial ecologists are dealt with in chapters on slow growth rates, mixed cultures, and growth on surfaces as microbial films. Finally, growth of colonies on solid media, and mathematical models of biomass autosynthesis are dealt with.

Microbial growth is usually treated as a biochemical phenomenon and many excellent textbooks are available which use this approach. The dynamics of cell growth, however, are usually given only superficial treatment; thus, Professor Pirt's book fills a much needed gap in the microbial literature. But both approaches have their merits and both types of book are needed to obtain a balanced viewpoint.

It would have been useful to widen the discussion a little more to show how the ideas outlined could be applied to specific problems. On several occasions the primary references to the subject are not given.

Overall Professor Pirt's book is a very useful addition to the microbial literature and should be read by all those interested in the dynamics of microbial and cell cultivation.

D. C. Ellwood
The New Mars: Discoveries of Mariner 9. By William K. Hartmann and Odell Raper. Pp. 179. (NASA Office of Space and Science: Washington, DC, 1974.) $\$ 8.75$.

THIS is in many ways the definitive book to emerge from the Mariner 9 adventure, produced with the cooperation of the Mariner 9 Science Exploration Team. As such it provides a well-written insight into one of the most successful scientific endeavours undertaken by man, and should be of interest to many people outside the circle of specialist astronomers and space scientists. For the price, it is worth having just to look at the lavish illustrations; serious planetary astronomers will not gain much from the text that has not already been published, but they may find the general overview of Mars useful, together with the bibliography provided in an appendix.

John Gribbin

\section{Books brief}

\section{Interfacial Electrochemistry: An} Experimental Approach. By E. Gileadi, E. Kirowa-Eisner and $J$. Penciner. Pp. xviii+525. (AddisonWesley: Reading, Massachusetts and London, June 1975.) Cloth \$19.50; paper $\$ 13.50$.

THIs book is divided into two sections, theoretical and practical. The theoretical section (150 pages) is a brief account of basic interfacial electrochemistry with three chapters covering corrosion, energy conversion and electroplating. The theoretical chapters succeed in the authors' aim of providing the fundamentals of electrode kinetics and double-layer theory; the other three chapters, however, are are inadequate and could well have been omitted.

The rest of the book is an excellent advanced practical text. Fourteen chapters describe current techniques of electrochemistry. The arrangement of the subject matter is good. Starting with the basic electronics (emphasis on op-amps) and reference electrodes, the reader is led through the majority of the important techniques of electrode kinetics and interphase studies applied to well defined systems. There are a few criticisms, ring-disc electrodes are omitted and impedance methods are not given sufficient space; electrometallurgy and electrocrystallisation are not dealt with. But these are of small importance, the main references are there at the end of each chapter and the reader is guided by the Authors to the major works of electrochemistry.

The book is a valuable addition to the literature of electrochemistry, and the price is reasonable by contemporary values.

N. A. Hampson

Normal Values in Clinical Chemistry: a Guide to Statistical Analysis of Laboratory Data. (Clinical and Biochemical Analysis: A Series of Monographs and Textbooks, Vol. 2.) By Horace F. Martin, Benjamin J. Gudzinowicz and Herbert Fanger. Pp. viii + 504. (Marcel Dekker: New York, May 1975.) $\$ 37.50$.

MORE and more pathology laboratory results, especially those of clinical chemistry, are numerical in form. Clinicians are accustomed to interpreting such results with the aid of the normal range, a range of values intended to include those to be expected from a large proportion (conventionally $95 \%$ ) of healthy individuals. This is clearly a statistical concept, and the statistical problems of estimating the limits of the normal range have received a good deal of attention. In fact these problems are quite straightforward; the real difficulties are logical ones, notably in deciding on what is meant by the "normal" population, and practical ones in obtaining the necessary data.

This book attempts to provide the clinical chemist with the statistical techniques needed to assess normal limits, but the attempt is far from successful. A very large literature, not all of it relevant, is extensively surveyed, but the uncritical approach and lack of logical organisation makes it almost impossible to follow the authors' drift. Explanations of the basic statistical principles vary from obscure to downright misleading. Even the practical problems are quite inadequately handled; it is never quite decided whether or not normal limits can be derived from data relating to hospital patients, and the large effects of the menopause on female biochemistry are not mentioned. Clinical chemists should wait for a better book on the subject, which should be considerably shorter and less expensive.
M. J. R. Healy 